\title{
A GEODIVERSIDADE DA REGIÃO DE PIRAÍ DA SERRA (PR)
}

\section{THE GEODIVERSITY OF PIRAÍ DA SERRA REGION IN THE PARANÁ STATE}

\author{
Nair Fernanda Mochiutti* \\ Rafael Köene** \\ Gilson Burigo Guimarães ${ }^{* * *}$ \\ Mário Sérgio de Melo****
}

\section{RESUMO}

A região de Piraí da Serra, um polígono que compreende segmentos dos municípios de Castro, Tibagi e Piraí do Sul, no reverso imediato da Escarpa Devoniana, contempla um rico patrimônio natural ainda preservado. Por conta disso, a área foi objeto de estudo de um projeto interdisciplinar desenvolvido por pesquisadores da Universidade de Ponta Grossa entre 2007 e 2009. O presente trabalho compreende os resultados do núcleo de estudos do meio físico, que teve como um de seus objetivos caracterizar a geodiversidade desta região. Para tanto, foram realizadas etapas de campo periódicas, fotointerpretação e análise de cartas topográficas, mapas geológicos e imagens de satélite além de extensa pesquisa bibliográfica. Em síntese, a geodiversidade de Piraí da Serra é representada por litologias da Bacia do Paraná, de seu Embasamento e do Magmatismo Serra Geral, com predomínio dos arenitos da Formação Furnas. Dentre as formas de relevo, destacam-se aquelas controladas pelo Arco de Ponta Grossa, como canyons, escarpamentos e cachoeiras, além das feições ruiniformes típicas da Formação Furnas esculpidas pela ação das águas pluviais. Como classes de solos, predominam os NEOSSOLOS LITÓLICOS, que juntamente com outros tipos constituem o resultado da pedogênese. Este mecanismo geológico, ao lado do ciclo hidrológico e demais ações geomórficas atestam o predomínio atual da operação de processos exógenos na região de Piraí da Serra, tais como intemperismo e erosão.

Palavras chave: Geodiversidade; Piraí da Serra; Campos Gerais do Paraná

\begin{abstract}
The region of "Piraí da Serra", on the boundaries of the municipalities of Castro, Tibagi and Piraí do Sul, is located at the dip slope of the Devonian Scarp and comprises a rich natural preserved heritage. For this reason, researchers from the Ponta Grossa State University carried out an interdisciplinary project from 2007 to 2009. This paper includes the results of the physical/natural study group, whose aim was to characterize the geodiversity of this region. To this end, periodic fieldwork was conducted, together with photointerpretation and analysis
\end{abstract}

\footnotetext{
${ }^{*}$ Universidade Federal de Santa Catarina (UFSC) E-mail: <fernandamochiutti@yahoo.com.br>

** Universidade Estadual de Ponta Grossa (UEPG) E-mail: <rafaelkoene@hotmail.com>

${ }^{* * *}$ Departamento de Geociências da Universidade Estadual de Ponta Grossa (DEGEO-UEPG) E-mail: <gburigo@ig.com.br>

***** Departamento de Geociências da Universidade Estadual de Ponta Grossa (DEGEO-UEPG) E-mail: <msmelo@uepg.br>
} 
of topographical, geological maps and satellite images, as well as an extensive literature review. In summary, the geodiversity of Piraí Sierra is represented by lithologies of the Paraná Basin, mainly Siluro-Devonian sandstones of the Furnas Formation, country rocks of the Castro Group, and also intrusive rocks related to the Cretaceous Serra Geral Magmatism. The Ponta Grossa Arch controlled the expression and development of the main landforms, such as canyons, escarpments and waterfalls, while the meteoric waters sculptured the typical ruiniform features of the Furnas Formation sandstones. The classes of soils that predominate are the Entisols, which along with other types of soil are the result of pedogenesis. This geological mechanism, together with the water cycle and other geomorphic actions, confirm the predominance of exogenous processes in the Piraí da Serra region, such as weathering and erosion.

Keywords: Geodiversity; Piraí da Serra region; Campos Gerais do Paraná.

\section{Introdução}

O conceito de geodiversidade faz referência à variedade de ambientes geológicos, fenômenos e processos ativos, geradores de paisagens, rochas, minerais, fósseis, solos e outros depósitos superficiais que constituem a base para a vida na Terra (GRAY, 2004; BRILHA, 2005). Este segmento do mundo natural é insubstituível e vital para a sustentação dos ecossistemas e da vida humana. É nas paisagens, nas rochas, nos fósseis que está escrita a história da Terra, num registro que constitui uma imensa reserva de ensinamentos sobre o modo como se processaram os diversos acontecimentos do planeta.

As ações voltadas para a conservação da geodiversidade dão corpo ao conceito de geoconservação (SHARPLES, 2002). Para que as mesmas se concretizem é necessário tornar conhecido o que existe em cada região, e a partir destas informações, buscar estratégias para a gestão adequada destes elementos.

A área de Piraí da Serra (Figura 1), localizada no domínio morfoestrutural do Segundo Planalto Paranaense, situa-se entre a Estrada do Cerne (rodovia PR-090) e o canyon do Rio Iapó, ao longo do reverso imediato da Escarpa Devoniana até o Rio Fortaleza-Guaricanga. Ela possui vários motivos de interesse natural, onde sobressaem aspectos geológicos e geomorfológicos, testemunhos de importantes acontecimentos que lá transcorreram, os quais até mesmo ultrapassam seus limites, alcançando repercussão regional, estadual ou continental. Estes aspectos abióticos são responsáveis por condicionar a beleza das paisagens e pela manutenção dos ecossistemas locais, influenciando também no desenvolvimento de certas atividades na região (por ex., pecuária, silvicultura etc.).

Piraí da Serra ganhou destaque em estudos realizados pela Universidade Estadual de Ponta Grossa (UEPG) entre os anos de 2000 e 2003, que a apontaram como um setor dos Campos Gerais com patrimônio natural bastante preservado (MELO et al., 2004). Este fato motivou a realização de projetos de pesquisa na área, entre os anos de 2007 e 2009, que em linhas gerais abrangeram estudos sobre a biodiversidade, geodiversidade e população local. A caracterização da geodiversidade e posteriormente a identificação de seus valores com base nas propostas de Gray (2004) foram os temas específicos que estimularam a construção do presente trabalho, o qual objetiva também contribuir para a divulgação e valorização das geociências e na fundamentação de ações geoconservacionistas a serem implementadas nesta área.

\section{Materiais e métodos}

Este trabalho é fruto de um período de dois anos de Iniciação Científica (2007-2009) dos dois primeiros autores, durante a graduação de ambos como bacharéis em Geografia pela UEPG. As atividades estiveram inseridas em um projeto interdisciplinar de maior âmbito, denominado "Diagnóstico ambiental da região de Piraí da Serra, visando a sustentabilidade regional", com financiamento da Fundação Araucária. O projeto foi organizado em 
núcleos de pesquisa (abiótico, biótico, arqueologia, cultural, sistemas de produção, educação ambiental), apresentando-se aqui parte dos resultados do núcleo abiótico.

Por conta do caráter interdisciplinar, esta pesquisa se beneficiou de informações que de alguma forma se fundiram com o tema geodiversidade, tais como:

a) estrutura fundiária da região e os diferentes usos do solo: permitindo identificar a distribuição das atividades em função das características do solo e do relevo e ameaças às quais a geodiversidade está sujeita; b) histórias de vida da população local: estabelecendo uma relação da identidade que as pessoas têm com esta área, em especial com a geodiversidade;

c) botânica: compreendendo como os diferentes tipos de vegetação estão condicionados à existência de determinados tipos de solo e de rocha;

d) arqueologia: relacionando a ocorrência de sítios de pinturas rupestres com os abrigos naturais nos afloramentos do Arenito Furnas.

As tarefas executadas compreenderam:

Figura 1 - Localização de Piraí da Serra - 1 Serra da Esperança; 2 Escarpa Devoniana; 3 Campos Gerais do Paraná; 4 Piraí da Serra.

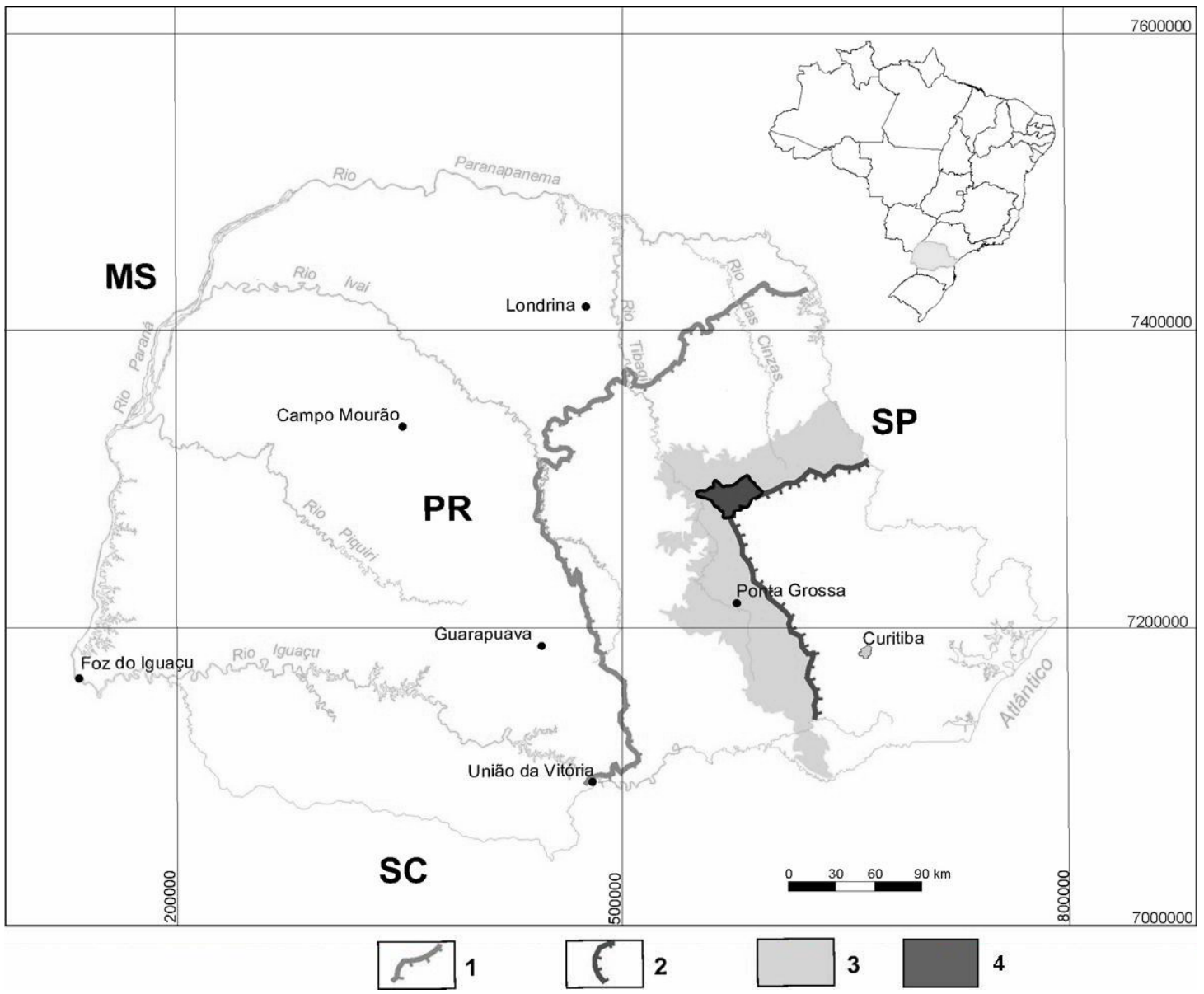

a) fotointerpretação a partir da análise de fotografias aéreas pancromáticas (faixas das fotos 2668, 2748-2760, 2812-2824, 4359-4363; escala 1:70.000, DGTC/Departamento de Geografia, Terras e Colonização do Estado do Paraná, 1962/1963) com uso de estereoscópios de mesa binoculares. Os padrões identifica- dos e interpretados foram controlados através do confronto com um mosaico formado por quatro ortoimagens com os respectivos MIs (mapa índices): 2807-3, 2807-4, 2824-1 e 2824-2. Estas apresentam resolução espacial de 5 metros e foram obtidas pela fusão das bandas multiespectrais (resolução espacial de 
10 metros) e pancromática (resolução espacial de 5 metros), do sensor SPOT 5 (data de 28 de julho de 2005). O mosaico das ortoimagens foi construído no programa ENVI 3.6. A etapa de trabalho com as fotografias aéreas e as ortoimagens (estas cedidas pelo PARANACIDADE/SEDU), teve como objetivo o reconhecimento da área de estudo (por exemplo, definição de rotas de deslocamento e aquisição de dados em campo) e a seleção de alvos representativos da geodiversidade local;

b) confecção de mapas temáticos de caracterização da área de estudo e de base para as etapas de campo utilizando o programa-livre SPRING 4.3.3, desenvolvido pelo INPE (Instituto Nacional de Pesquisas Espaciais). As vias de acesso e a hidrografia foram digitalizadas com base no mosaico de ortoimagens SPOT 5, já referidas, e cartas topográficas do Ministério do Exército - Folha Monte Negro SG 22-X-A-II-4 MI 2807/4 e Folha Rincão da Ponte SG 22-X-A-II-3 MI 2807/3 - 1:50.000 de 1996. A partir destas cartas também foram compilados dados referentes à toponímia. A geologia teve como base a carta geológica Folha Telêmaco Borba SG-22-X-A em escala 1:250.000 (meio digital) de 2006 da MINEROPAR (Minerais do Paraná). As principais feições geomorfológicas da área foram obtidas por meio das fotos aéreas, utilizando os estereoscópios de mesa binoculares e folhas de acetato, as quais foram digitalizadas no programa SPRING. As classes de solos foram obtidas a partir do levantamento semidetalhado de solos dos municípios de Tibagi, Castro e Piraí do Sul em escala 1:100.000 (meio digital) de 2002 da EMBRAPA (Empresa Brasileira de Pesquisa Agropecuária). Utilizou-se para todos os mapas a Projeção UNIVERSAL TRANSVERSA DE MERCATOR (UTM), Datum horizontal Imbituba (SC) e Datum vertical SAD 69 (MG);

c) reconhecimento em campo da área de estudo com a identificação e descrição dos diferentes componentes da geodiversidade local, discriminados em categorias que levaram em conta as suas particularidades estratigráficas (por exemplo, afloramentos da Formação Iapó ou membros da Formação Furnas), geomorfológicas (por ex., canyons, cachoeiras), paleontológicas (por ex., icnofósseis da Formação Furnas), etc.;

d) aquisição das coordenadas de locais representativos da geodiversidade, estradas, florestamentos, vegetação nativa e propriedades rurais com a utilização de um receptor GPS (Global Positioning System) - Garmin ${ }^{\mathrm{TM}}$, modelo eTrex Legend. Datum vertical Imbituba (Santa Catarina), Datum horizontal SAD 69 (Minas Gerais), Projeção UNIVERSAL TRANSVERSA DE MERCATOR.

\section{Resultados e discussão}

A caracterização da geodiversidade apresenta os produtos e processos englobados pelo conceito de geodiversidade e que são identificáveis na região de Piraí da Serra, abordando assim a geologia, pedologia e geomorfologia, além dos processos físicos reconhecidos na área de estudo.

\section{Geologia}

A geologia de Piraí da Serra é representada por litologias do Embasamento da Bacia do Paraná, da Bacia do Paraná e do Magmatismo Serra Geral (Figura 2).

Os afloramentos do embasamento estão relacionados aos contatos com a Bacia do Paraná e são representados pelas rochas vulcânicas e sedimentares do Grupo Castro, que de acordo com Melo, Guimarães e Santana (2010) possui idade precariamente estabelecida, próximo ao limite entre o Proterozoico e o Paleozoico. As rochas sedimentares da Bacia do Paraná correspondem a materiais do Ordoviciano-Siluriano e do Devoniano. Da base para o topo são elas: Formação Iapó, pertencente ao Grupo Rio Ivaí (Ordoviciano-Siluriano) e as formações Furnas e Ponta Grossa, pertencentes ao Grupo Paraná (principalmente Devoniano). Adicionalmente aparecem as rochas intrusivas básicas relacionadas ao Magmatismo Serra Geral, de idade mesozoica, cortando as unidades pré-existentes (MILANI et al., 2007).

\section{Grupo Castro}

O Grupo Castro é uma bacia vulcanossedimentar, com uma abrangência de $900 \mathrm{~km}^{2}$, que 
remonta ao final do Ciclo Brasiliano, aflorante nos arredores de Piraí do Sul e Castro (TREIN; FUCK, 1967).

Os afloramentos do Grupo Castro na área de estudo são encontrados junto à Escarpa Devoniana e no leito do Rio Iapó no Canyon do Guartelá, em contato erosivo com a Bacia do Paraná. Em um afloramento da base do Arenito Furnas, no ponto 1 (ver Figura 2 para a localização dos pontos mencionados ao longo do texto), as rochas encontram-se bastante alteradas, sendo difícil definir com precisão se existe uma passagem direta para o Grupo Castro ou se também ocorrem rochas da Formação Iapó, registrando-se apenas a presença de clastos dispersos em matriz argilosa, provavelmente ligados a depósitos de colúvios.
No afloramento do ponto 2, o contato se dá entre arenitos da Formação Furnas e riolitos bastante alterados. Estes apresentam sinais de hidrotermalismo (por exemplo, vênulas preenchidas por material argiloso) e fraturas de natureza tectônica. O hidrotermalismo consiste em uma alteração dos minerais (hidratação e/ou lixiviação) e consequentemente das rochas, por fluidos aquosos aquecidos normalmente por fenômenos ígneos. Estes riolitos, assim como rochas piroclásticas, estão associados a uma sequência vulcânica predominantemente ácida, que de acordo com Trein e Fuck (1967) contém rochas extremamente variadas em seu aspecto macroscópico, principalmente do ponto de vista textural.

Figura 2 - Mapa geológico de Pirai da Sera (PR)

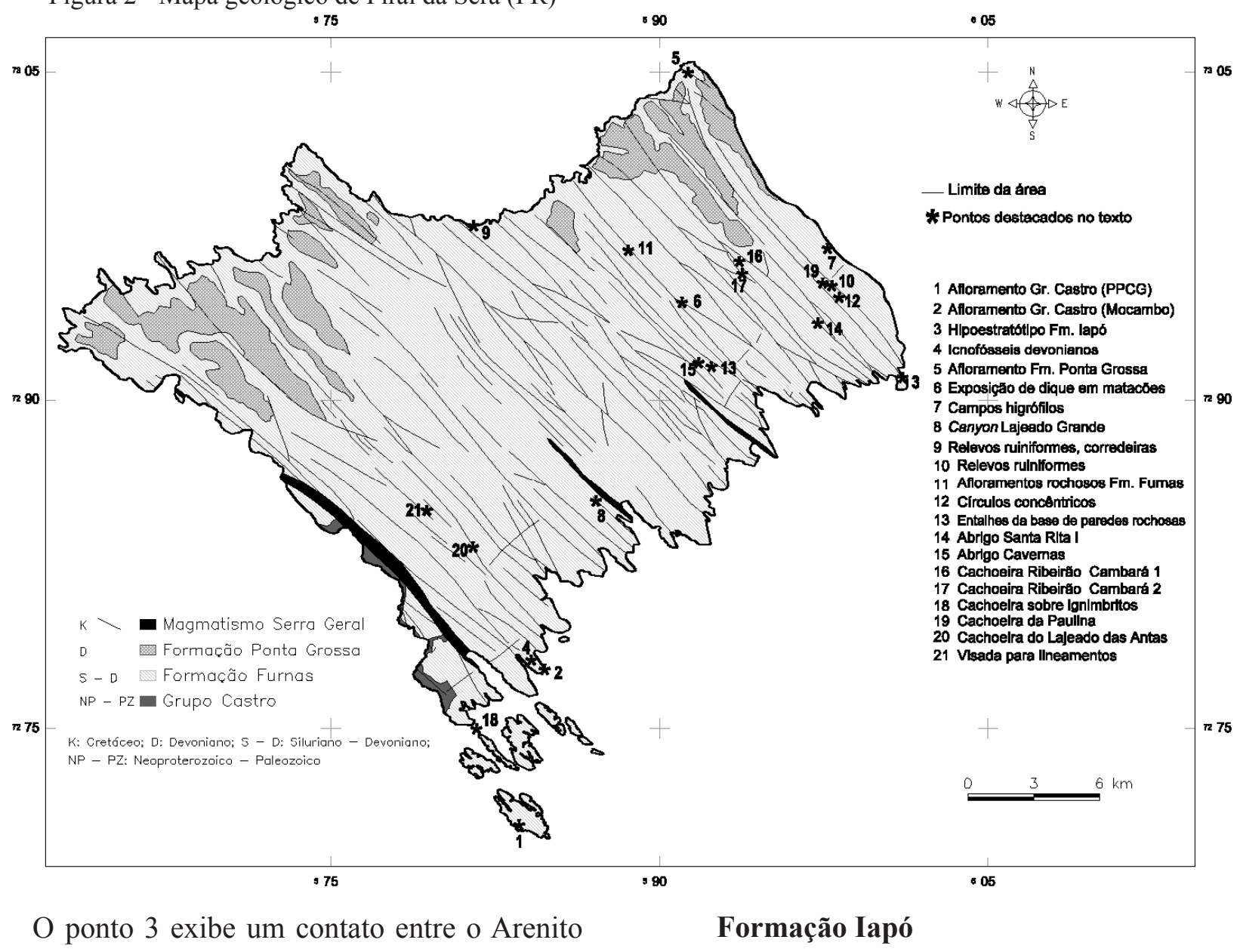

Furnas e diamictitos da Formação Iapó e destes com siltitos pertencentes à sequência sedimentar do Grupo Castro, ostentando colorações variadas e uma grande quantidade de minerais micáceos (muscovita).

Esta unidade foi definida por Maack em 1947, na Serra de São Joaquim, no quilômetro 16 da Rodovia PR-340 que liga Castro a Tibagi, em um local situado nas proximidades de Piraí da Serra. O autor a con- 
siderou como de origem glacial e de idade siluriana, caracterizando-a em fácies distintas: diamictitos avermelhados de matriz arenosa sobrepostos por diamictitos cinza-azulados e matriz síltico-arenosa.

Afloramentos desta formação são bastante raros, por se tratar de uma unidade pouco espessa, normalmente inferior a 20 metros, e também descontínua, frequentemente coberta por depósitos de tálus (ASSINE; ALVARENGA; PERINOTTO, 1998).

O único local onde foi identificado um afloramento desta unidade na área de estudo foi em um corte da Rodovia PR-090, junto ao ponto 3. Este afloramento bastante representativo já havia sido descrito por Vieira (1973), onde a Formação Iapó (diamictitos e arenitos muito finos) assenta em discordância angular sobre as rochas sedimentares do Grupo Castro (siltitos), consideradas como de idade ordoviciana pelo autor.

\section{Formação Furnas}

A Formação Furnas é composta de rochas originadas desde o final do Siluriano até o início do Devoniano, provavelmente em ambiente transicional a marinho. Caracterizada por camadas tabulares e com espessuras de aproximadamente $250 \mathrm{~m}$ no Canyon do Guartelá, geralmente é descrita como uma sucessão monótona de arenitos quartzosos portadores de estratificação cruzada, aos quais se intercalam delgados níveis de conglomerados, sobretudo na sua porção basal (GUIMARÃES et al., 2007). Assine (1996), com base em um estudo mais detalhado, caracterizou-a em três unidades, designadas da base para o topo como unidades I, II e III, posteriormente referidas como inferior, média e superior (ASSINE, 1999).

A Formação Furnas é a unidade geológica com maior representatividade em Piraí da Serra, com exposições de rocha em quase todo o seu domínio, especialmente no trecho mais próximo à Escarpa Devoniana, rareando a partir da metade do caminho em direção ao Rio Fortaleza-Guaricanga. Em sua maioria são afloramentos em escarpamentos, lajes, blocos de arenitos isolados, principalmente nos topos aplainados ou espigões que sucedem os canyons. Alguns locais se assemelham a verdadeiras cidades-de-pedra, exibindo diversas características típicas desta unidade litológica, como estratificações cruzadas, intercalações de níveis conglomeráticos e feições de geomorfologia cárstica (relevo ruiniforme, alvéolos, bacias de dissolução, caneluras, labirintos, torres, lapas, etc.).

Não é uma característica da Formação Furnas a presença de organismos ou moldes fósseis de invertebrados, mas a ocorrência de icnofósseis é relativamente comum. Como já destacado na descrição de Assine (1996), estas ocorrências geralmente acontecem na Unidade Média. Alguns dos icnogêneros mencionados com mais frequência na Formação Furnas são Furnasichnus, Rusophycus, Cruziana, Paleophycus e Planolites (ASSINE, 1999; FERNANDES et al., 2002).

No ponto 4, um afloramento da Formação Furnas apresenta uma laje de arenito onde há a presença de muitos traços sinuosos com topos unilobados com espessuras de 2 a $3 \mathrm{~cm}$ e material de preenchimento idêntico ao restante da rocha. Ao que tudo indica tratam-se de traços fósseis do icnogênero Paleophycus, correspondendo então a icnitos de habitação e/ou alimentação.

\section{Formação Ponta Grossa}

A Formação Ponta Grossa é a unidade sedimentar mais recente da Bacia do Paraná em Piraí da Serra. A ausência de exposições mais abundantes (naturais ou artificiais) e menos afetadas pelo intemperismo deve-se tanto à sua composição mineralógica como ao tipo de relevo desenvolvido sobre estas litologias. As colinas suaves e com solos relativamente profundos, típicas das áreas cujo substrato é esta unidade, normalmente não determinam a realização de obras civis que promovam seções profundas no terreno (como ocorre localmente com a Formação Furnas) durante a implantação das estradas rurais. $\mathrm{O}$ afloramento do ponto 5 está marcado por feições de tectonismo (fraturas de direção N35-40W subverticais, relacionadas ao desenvolvimento do Arco de Ponta Grossa). Apesar desta unidade ser notoriamente fossilífera, um baixo número de fósseis foi identificado neste afloramento (dois exemplares de braquiópodes articulados do gênero Australocoelia), fato possivelmente relacionado às suas condições (grau de alteração, espessura) mas também à observação expedita realizada. No entanto a confirmação da ocorrência destes fósseis, mesmo que em pequeno número, permite reconhecer o ambiente marinho em que estas rochas foram formadas. 


\section{Magmatismo Serra Geral}

A geologia e o relevo de Piraí da Serra sofreram a influência de um evento tectônico denominado Arco de Ponta Grossa, cujo período de máxima atividade foi durante o Mesozoico (GUIMARÃES et al., 2007). Este evento corresponde a um soerguimento da crosta terrestre com eixo na direção NW-SE, quando os continentes sul-americano e africano se separaram, afetando principalmente a região onde hoje temos o Estado do Paraná. Este arqueamento da crosta deu origem a várias fraturas que foram preenchidas por magma predominantemente basáltico (Magmatismo Serra Geral), na forma de corpos magmáticos chamados de diques, que na área de estudo abriga uma das maiores concentrações do mundo. Estes diques formam um espetacular enxame orientado na direção NW-SE, com até 40 diques numa extensão de $25 \mathrm{~km}$. Os maiores diques têm cerca de $400 \mathrm{~m}$ de espessura e superam $42 \mathrm{~km}$ de extensão (KÖENE et al., 2008). As rochas que compõem estes diques possuem uma variação composicional e textural: diabásios, dioritos, dioritos pórfiros e quartzo dioritos. Segundo Marini; Fuck e Trein (1967) estes tipos de rochas básicas são consanguíneas, pertencentes à província magmática basáltica toleítica (quartzo-diabásios) do Brasil Meridional. São rochas contemporâneas e com idade posicionada entre 137 e $127 \mathrm{Ma}$, no início do Cretáceo (MILANI et al., 2007).

Os diabásios são as rochas de maior ocorrência nos diques da região. Afloram geralmente na forma de matacões arredondados e lisos como acontece no ponto 6 , com aproximadamente $1 \mathrm{~m}$ de diâmetro ou menos (porém em algumas situações podem ser maiores), sendo este tipo litológico conhecido popularmente como "pedra-ferro". A forma arredondada é o resultado da esfoliação esferoidal, comum a esta rocha (MARINI; FUCK; TREIN, 1967). Sua coloração varia de cinza-escuro a preto e sua composição é essencialmente de plagioclásio e clinopiroxênio, com granulação fina a média.

\section{Solos}

Os dados referentes aos tipos de solos e sua distribuição em Piraí da Serra foram baseados nas descrições de Sá (2007) sobre os solos dos Campos Gerais, além das informações colhidas nos mapas de solos dos municípios de Tibagi, Castro e Piraí do Sul, da EMBRAPA (2002). As etapas de campo permitiram a identificação de alguns dos tipos de solos relacionados abaixo e também a conferência da distribuição dos mesmos no mapa previamente elaborado. No entanto, a descrição se baseia essencialmente no material bibliográfico e cartográfico.

O material de origem dos solos presentes em Piraí da Serra é constituído pelos arenitos da Formação Furnas, folhelhos, argilitos e siltitos da Formação Ponta Grossa, além das rochas intrusivas básicas do Magmatismo Serra Geral, como o diabásio. A distribuição dos diferentes tipos de solos encontrados é influenciada pelos litotipos e principalmente pela configuração do relevo, aliados a toda gama de fatores exógenos responsáveis pela formação dos solos.

\section{NEOSSOLOS}

Os NEOSSOLOS correspondem a solos pouco desenvolvidos, sem qualquer tipo de horizonte B. Segundo Sá (2007) isso pode acontecer pela baixa intensidade de atuação dos processos pedogenéticos, resistência do material de origem ao intemperismo, condições de relevo, os quais isoladamente ou em conjunto, limitaram a evolução destes solos.

Em Piraí da Serra, a subordem que ocorre é dos NEOSSOLOS LITÓLICOS. São solos rasos ou muito rasos, com horizonte A assentado diretamente sobre a rocha. Sua limitação está na pequena profundidade, que restringe o desenvolvimento radicular das plantas e culturas, sendo assim deficiente para a sustentação da vegetação de maior porte com sistema radicular mais profundo e apresentando pouca fertilidade para o uso agrícola. A vegetação característica nas áreas de ocorrência deste tipo de solo é a campestre, neste caso, representada por campos secos ou rochosos (aliados a afloramentos de arenitos). Estas áreas estépicas são formas relictas de um antigo clima semi-árido pleistocênico, sendo a formação florística mais antiga ou primária do Estado do Paraná (NANUNCIO; MORO, 2008).

Os NEOSSOLOS LITÓLICOS estão localizados em áreas de maior declividade e sobre os topos aplainados, principalmente sobre a Formação Furnas. É a ordem de solos que ocorre com mais frequência junto à borda da Escarpa Devoniana. 
Sua textura arenosa a média, aliada a pouca profundidade e as altas declividades, a tornam bastante susceptível à erosão, caracterizando um solo de alta fragilidade.

\section{CAMBISSOLOS}

Compreendem solos pouco desenvolvidos com horizonte A de qualquer tipo e horizonte B incipiente (não muito expressivos). Possuem textura média quando oriundos dos arenitos e textura argilosa a muito argilosa quando provindos dos folhelhos e argilitos. Exibem, normalmente, amplo contraste de cores entre os horizontes, devido ao elevado teor de matéria orgânica no horizonte superficial (SÁ, 2007).

Os CAMBISSOLOS estão relacionados a áreas mais movimentadas, de relevos dissecados e ondulados em interflúvios estreitos de vertentes mais curtas e abruptas, assim como nos terços inferiores das vertentes, nas proximidades das redes de drenagem e de planícies (SÁ, 2007). São representados na área pelas subordens CAMBISSOLO HÁPLICO (CX) e HÚMICO $(\mathrm{CH})$, os quais se diferenciam pela maior profundidade do horizonte $\mathrm{A}$ e/ou pela rica presença de matéria orgânica nos $\mathrm{CH}$. São solos de boa produtividade quando bem manejados, e utilizados para atividades de agricultura e pecuária. Como se encontram principalmente em cabeceiras de drenagem, abrigam uma cobertura vegetal natural de maior porte e mais densa.

\section{LATOSSOLOS}

Constituem uma ordem de solos profundos a muito profundos com espessura geralmente superior a $2 \mathrm{~m}$. Têm elevado grau de desenvolvimento pedogenético, onde predomina a fração argila. São em geral bem drenados, bem estruturados e porosos, com pequena diferenciação entre os horizontes (SÁ, 2007). As subordens presentes na região de Piraí da Serra são três: LATOSSOLO VERMELHO (LV), LATOSSOLO VERMELHO-AMARELO (LVA) e LATOSSOLO BRUNO (LB).

Os LV são bastante homogêneos, bem drenados, de coloração vermelha escura. A textura é argilosa a muito argilosa, ocorrendo em um relevo suave ondulado, em paisagens mais aplainadas. São solos desenvolvidos principalmente sobre a Formação
Ponta Grossa nas partes noroeste e nordeste da área. Mesmo não possuindo fertilidade natural elevada, são largamente utilizados na agricultura, exigindo a aplicação de corretivos e fertilizantes. Os LVA geralmente apresentam uma textura média com bom suprimento de matéria orgânica. São bem drenados, possuem cores vermelho-amareladas e são de baixa fertilidade natural. Em Piraí da Serra, estes tipos de solos em geral estão associados a um relevo suave ondulado, favorável à mecanização, sendo por isso utilizados para atividades agrícolas. Os LB são solos profundos, com horizonte A mais escuro e em geral espesso, o horizonte subsuperficial apresenta tons brunados (acastanhados) com avermelhamento em maior profundidade. São solos argilosos ou muito argilosos com alta capacidade de retração diante da perda de umidade.

\section{ARGISSOLOS}

São solos minerais, com horizonte A ou E seguido de horizonte B textural, com nítida diferença entre os horizontes. As profundidades são variadas e possuem ampla variabilidade de classes texturais. É característica deste tipo de solo aparecer associado ou próximo a CAMBISSOLOS, que é o caso em Piraí da Serra, onde um pequeno setor de ARGISSOLO VERMELHO AMARELO, na porção nordeste da área, aparece em associação a CAMBISSOLOS.

Geralmente os ARGISSOLOS estão presentes em relevos mais ondulados ou ocupam o terço médio inferior das vertentes, precedidos pelos LATOSSOLOS, estes nas porções mais planas e bem drenadas da paisagem (SÁ, 2007). Estão assentados sobre rochas das formações de Ponta Grossa e Furnas, nesta última com material remobilizado da Formação de Ponta Grossa. Este tipo de solo apresenta fertilidade natural baixa, requerendo altas doses de fertilizantes e corretivos. Também possuem alta suscetibilidade à erosão.

\section{ORGANOSSOLOS}

São solos constituídos por material orgânico proveniente de acumulações de restos de vegetais em grau variável de decomposição, situados em ambientes mal a muito mal drenados ou em ambientes úmidos de altitude elevada (HORNES, 2006). Localizam-se também em áreas de várzea e depressões 
no relevo, as quais acumulam água e permanecem constantemente encharcadas. Sua coloração é preta, cinza-escura e marrom, com elevados teores de carbono orgânico e baixa saturação por bases. Apresentam horizonte $\mathrm{H}$ ou $\mathrm{O}$ hístico com espessura mínima de $40 \mathrm{~cm}$. São encontrados também em relevos ondulados e suave ondulados nas vertentes côncavas convergentes, ou mesmo na base das vertentes em geral, onde estão associados com a surgência hídrica (SÁ, 2007).

$\mathrm{Na}$ área de estudo esta classe de solos aparece em manchas onde o nível freático é superficial ou em porções mais deprimidas do terreno, que comumente acumulam água durante os períodos chuvosos. Possuem relação direta com a ocorrência dos campos úmidos, como é o caso do ponto 7.

\section{Geomorfologia}

Um dos fatores endógenos de maior influência no modelado do relevo em Piraí da Serra e que tem participação no condicionamento das atividades antrópicas na área é o Arco de Ponta Grossa. Em conjugação a este evento geológico estão os fatores exógenos, representados principalmente por processos de intemperismo e erosão. Os diversos tipos de feições variam em diferentes escalas de observação, sendo representados segundo Melo et al. (2007) por dois tipos principais:

a) macro-feições da paisagem, tais como escarpamentos, canyons e morros-testemunhos;

b) meso- e micro-feições derivadas de processos erosivos atuantes sobretudo em arenitos da Formação Furnas, tais como relevos ruiniformes, torres e pináculos, fendas e labirintos, caneluras, bacias de dissolução, alvéolos, entalhes da base de paredes rochosas, cachoeiras, corredeiras e lapas.

\section{Arco de Ponta Grossa}

A área de Piraí da Serra encontra-se justamente sobre o eixo do Arco de Ponta Grossa, constituindo a faixa de uma das maiores concentrações de diques de rochas básicas do mundo (ver descrição acima), que correspondem a corpos ígneos alojados em muitas das falhas e fraturas advindas do próprio arqueamento. Dado o seu grande número, esses di- ques constituem um dos principais fatores de controle do modelado do relevo da área. O condicionamento do relevo pelo tectonismo tem como um dos principais indicadores a rede de drenagem, a qual apresenta um forte paralelismo na faixa onde o enxame de diques é mais denso. Assim, segundo Marini; Fuck e Trein (1967), o recuo da escarpa sustentada pelos arenitos da Formação Furnas na porção central do Arco de Ponta Grossa, seria guiado pelos rios consequentes e obsequentes, posicionados sobre diques. A ação erosiva fluvial é mais eficiente nas rochas ígneas, as quais são mais suscetíveis do que a rocha encaixante, no caso o Arenito Furnas. Desta forma, estes cursos d'água escavam facilmente os seus leitos, muitas vezes rompendo a escarpa e originando canyons com vertentes bastante abruptas. Como consequência do recuo da escarpa, originam-se festões alongados segundo a direção das rochas intrusivas, além de morros-testemunhos.

\section{Feições do relevo}

A descrição das formas de relevo da área de estudo teve como base as considerações de Melo (2006) e Melo et al. (2007), referentes ao Parque Estadual de Vila Velha e a toda região dos Campos Gerais, adaptadas ao caso específico de Piraí da Serra.

\section{Escarpas}

Os escarpamentos constituem paredes rochosas verticalizadas que na região são sustentadas pelo Arenito Furnas. O Escarpamento Estrutural Furnas ou Escarpa Devoniana corresponde à principal feição deste tipo na área, podendo ocorrer também ao longo de canyons e outros desníveis. Esta estrutura representa um importante degrau topográfico que separa o Primeiro do Segundo Planalto Paranaense. Estende-se por cerca de $260 \mathrm{~km}$, entre os estados de São Paulo e Paraná, apresentando amplitudes principalmente entre 100 e $200 \mathrm{~m}$ e altitudes médias em torno de 1100-1200 m (SOUZA, C.; SOUZA, A., 2002). Em Piraí da Serra sua extensão é de aproximadamente $25 \mathrm{~km}$, compreendida entre os municípios de Piraí do Sul (PR-090) e Tibagi (Rio Iapó) com exposições de toda a sequência sedimentar da Formação Furnas (ASSINE, 1996) e de seus contatos discordantes com a Formação Iapó e o Grupo Castro. 
Seu desenvolvimento está associado aos processos geodinâmicos iniciados com a ruptura do Gondwana (Jurássico) e continuados com longos processos de erosão diferencial ligados a condições climáticas áridas/semi-áridas e quentes, ocorridas durante o Cretáceo Superior e o Paleógeno (SOUZA, C.; SOUZA, A., 2002). De mesmo modo, sua configuração curvilínea também está associada ao alto estrutural do Arco de Ponta Grossa. Sua amplitude a torna uma feição facilmente identificável em fotografias aéreas, imagens de satélite e mapas topográficos.

\section{Canyons}

Os canyons são gargantas retilíneas escavadas pelos rios que vencem a escarpa, controladas por longas estruturas rúpteis (falhas, fraturas) ligadas ao Arco de Ponta Grossa, às vezes encaixando diques de diabásio e rochas filiadas de direção NW-SE. Estas estruturas atingem grandes profundidades e extensões, e se distribuem de forma uniforme pela área na faixa correspondente à Formação Furnas. Isto se deve ao fato de que o Arenito Furnas possui um comportamento reológico rúptil, marcado pela presença de falhas e fraturas que constituem "linhas" de fraqueza, condicionando a drenagem no sentido NW-SE. Os canyons terminam no contato entre as formações Furnas e Ponta Grossa, uma vez que os folhelhos possuem um comportamento plástico e não proporcionam um intemperismo diferencial marcante em comparação com as rochas ígneas dos diques, determinando assim um relevo pouco contrastante.

Dentre aqueles de maiores proporções estão o Canyon do Rio Iapó, Palmeirinha, Lajeado Grande no ponto 8 e Itaytyba. Os canyons de direção NE-SW possuem menores dimensões e aparecem em menor concentração, comprovando a geração de estruturas NE e/ou sua reativação durante a evolução do arqueamento. As vertentes bastante abruptas e próximas exibem os diferentes estratos da Formação Furnas. A presença, no fundo dos canyons, de umidade e muitas vezes de solo advindo da decomposição dos diques, condiciona uma vegetação mais densa, de maior porte. À medida que avançam pelo reverso da escarpa na direção noroeste, estas estruturas vão se suavizando, e o relevo já não se apresenta tão movimentado.

\section{Morros-testemunhos}

Os morros-testemunhos correspondem a elevações no terreno, geralmente de formato arredondado, que se destacam na topografia em função da ação erosiva circundante, que entalha e rebaixa o relevo nos vales (MELO, 2006). Como está expresso em sua denominação, estas formas atestam a extensão original das rochas previamente à erosão. Isso se dá pela resistência das rochas que as sustentam, no caso o Arenito Furnas. Os festões alongados que se originam do recuo da escarpa quando da formação dos canyons, a partir de processos continuados de erosão, podem evoluir para morros-testemunhos em descontinuidade com o restante do escarpamento. Este tipo de feição é encontrado na parte sudoeste da área, próximo aos pontos 4 e 2 . Geralmente possuem topos aplainados onde se percebe que a vegetação campestre encontra-se preservada, muito pela dificuldade de acesso ao topo ou pela inviabilidade de uso destes locais.

$\mathrm{O}$ aplainamento dos platôs é devido à combinação de dois fatores: a erosão que removeu as rochas que no passado encontravam-se acima das superfícies de topos atuais e a existência de estruturas sedimentares (contato entre camadas e unidades rochosas) sub-horizontais, que ajudam a definir níveis que controlam o avanço da erosão e favorecem a formação dos aplainamentos topográficos (MELO, 2006), característicos também na sucessão dos canyons que cortam a área. $\mathrm{O}$ contraste que possuem estas feições em relação ao restante da topografia confere a esta paisagem um interessante destaque, fator que leva à atribuição de forte apelo estético às mesmas.

\section{Relevos ruiniformes}

As rochas submetidas à ação dos processos erosivos se desfazem de modo disforme, assumindo aspecto de ruínas, como de uma antiga construção submetida às intempéries e ao passar do tempo. A desagregação dos arenitos gera muitos tipos de ornamentações, esculturas e entalhes que podem variar de milímetros a dezenas de metros (MELO, 2006). Este tipo de ocorrência engloba na verdade uma série de feições de dissolução, como torres e pináculos, fendas e labirintos, caneluras, bacias de dissolução, alvéolos, entalhes da base de paredes 
rochosas e lapas. A descrição destas feições se baseia essencialmente nos trabalhos de Melo (2006) e Melo et al. (2007) com a indicação da ocorrência das mesmas na área de estudo.

\section{Torres e pináculos}

As torres constituem-se de colunas de rocha, geralmente com a parte basal mais estreita, geradas pelo constante aprofundamento da erosão mecânica combinada à dissolução ao seu redor, o que acaba por isolar o bloco rochoso do maciço circundante. Este processo é facilitado por fraturamentos e pelo escoamento da água meteórica concentrada em canais ou canaletas na rocha. A ocorrência destas feições foi testemunhada em uma área consideravelmente extensa de afloramentos rochosos da Formação Furnas no ponto 9.

Os pináculos são irregularidades características dos topos dos maciços areníticos, os quais encontram-se corroídos e apresentam muitas terminações pontiagudas e salientes, também ocasionadas por processos erosivos de dissolução e remoção mecânica da rocha. Lembram as torres e fortificações de castelos. São comumente observados nos topos dos blocos rochosos dos pontos 10 e 11 .

\section{Fendas e labirintos}

Estas feições derivam do aprofundamento erosivo de fraturamentos do terreno, pela ação das águas da chuva que geralmente escoam na forma de fluxo d'água ou enxurrada. Um sistema de fendas com mais de uma direção caracteriza os labirintos. Este sistema de feições acontece nos pontos 11 e 9 .

\section{Caneluras}

A concentração da água da chuva que escoa sobre os blocos de arenito acaba formando reentrâncias alongadas na forma de sulcos ou canais de drenagem, os quais variam de dimensões milimétricas a profundidades maiores. O processo erosivo envolvido no entalhamento destes canais associa erosão mecânica e dissolução, esta influenciada pela presença de ácidos orgânicos em solução na água. Foram encontradas feições deste tipo no caminho para a Cachoeira da Paulina, próximo ao ponto 11, com ocorrência também no ponto 12 .

\section{Bacias de dissolução}

Depressões naturais em lajes de arenito podem acumular a água da chuva. Essa água estagnada, enriquecida com ácidos orgânicos advindos da decomposição de organismos que proliferam nessas poças acelera a desagregação da rocha, dissolvendo o cimento que une os grãos. As depressões naturais vão se aprofundando, dando origem às bacias ou panelas no arenito. É comum encontrar estas feições com água acumulada, o que permite o desenvolvimento de criadouros de diversos organismos, tais como larvas de mosquito. As bacias de dissolução são facilmente encontradas, principalmente nas lajes do arenito e no topo dos blocos rochosos. O ponto 4 exibe uma grande concentração destas feições.

\section{Alvéolos}

Os alvéolos são reentrâncias na superfície rochosa, geralmente nas paredes da rocha, mas podendo ocorrer também no piso do arenito. Semelhante às outras feições, estas estruturas também se desenvolvem por conta da ação do escoamento da água da chuva, que provoca a remoção dos grãos e a dissolução do cimento do arenito. Soma-se a isso a ação de organismos como liquens e musgos, que comumente fazem deste tipo de rocha seu hábitat (ambiente rupícola). $\mathrm{O}$ controle estratigráfico também influencia no aparecimento dos alvéolos. Níveis em que as características de textura e cimentação da rocha a tornem mais vulnerável ao intemperismo podem concentrar este tipo de feição. Destaca-se a ocorrência de alvéolos no ponto 11 .

\section{Entalhes da base de paredes rochosas}

O entalhamento ocorre como uma reentrância côncava na base de paredes rochosas de blocos isolados de arenito. O contato direto com o solo sugere a influência da infiltração de umidade por capilaridade ou vinda das partes mais elevadas do maciço, que satura os poros facilitando as reações químicas, a proliferação de organismos e a erosão. Este processo é aguçado principalmente pela erosão diferencial, que em função das diferentes características da rocha em seus diferentes níveis não desgasta o bloco de uma forma homogênea. Algumas das formas mais comuns geradas são os chamados "cogumelos" 
como as famosas "Pedras Gêmeas" na RPPN de Itaytyba e uma ocorrência bastante representativa em um espigão próximo ao ponto 13.

\section{Lapas}

As lapas são reentrâncias em locais escarpados e paredes rochosas que formam abrigos naturais, com um teto rochoso saliente que protege das intempéries. Sua ocorrência na área de estudo está ligada ao Arenito Furnas, originando-se pela queda dos blocos de rocha pelo efeito combinado da presença das estruturas rúpteis e da erosão diferencial (contraste erosivo em função das diferenças de textura e/ou grau de cimentação das rochas).

É comum a localização estratégica destas lapas, próximas a cursos d'água e florestas, fato que as tornaram favoráveis para abrigo de antigos indígenas que habitaram esta região, os quais deixaram seus registros expressos através de pinturas nas rochas e artefatos líticos. Dos 14 abrigos sob rocha descritos em Piraí da Serra, os mais conhecidos são o Abrigo Santa Rita I (ponto 14) e II, Abrigo Chapadinha I e II, Abrigo Paulino I, II e III e o Abrigo Cavernas no ponto 15 (PEREIRA, 2009a, 2009b).

\section{Cachoeiras e corredeiras}

A ocorrência de cachoeiras e corredeiras é bastante comum na região de Piraí da Serra. Durante as incursões em campo foram identificadas oito cachoeiras de maior porte e outras quedas menores, como a sequência de quedas dos pontos 16 e 17. Por conta da densidade de drenagens e dos desníveis do relevo, existe potencial para um número ainda maior de cachoeiras do que o aqui indicado. Com exceção de uma cachoeira no ponto 18 em que o leito do rio é constituído por ignimbritos do Grupo Castro, todas as outras quedas ocorrem sobre rochas da Formação Furnas. Este fato se dá pela marcante presença de estruturas sedimentares e rúpteis e também em virtude das variações na constituição litológica, que determinam diferentes comportamentos frente aos processos erosivos, favorecendo a formação de degraus no leito dos rios (MELO, 2006). As corredeiras podem ser vistas no ponto 9 e no Arroio da Bomba, em Itaytyba. As maiores quedas estão associadas aos desníveis dos canyons e fraturas como a Cachoeira da Paulina, no ponto 19 (aproximadamente $40 \mathrm{~m}$ ),
Cachoeira do Lajeado das Antas no ponto 20 (aproximadamente $20 \mathrm{~m}$ ), Cachoeira dos Macacos (aproximadamente $70 \mathrm{~m}$ ) e Cachoeira do Canyon da Bomba (aproximadamente 72 m) (HORNES, 2003).

\section{Lineamentos}

A forte influência da evolução do Arco de Ponta Grossa na área de Piraí da Serra gerou muitas estruturas tectônicas, as quais edificam tanto os traços maiores do relevo como detalhes visíveis somente na escala de afloramento. Os lineamentos são traços retilíneos bastante perceptíveis em fotografias aéreas ou imagens de satélite, representados por faixas com vegetação mais densa e de maior porte, presença de água e depressões. Sua ocorrência revela a existência de fraturas, falhas ou diques em superfície. A vista do ponto 21 permite a identificação de várias destas feições em diferentes direções.

\section{Processos geológicos}

Existem processos geológicos que devido a sua magnitude e rapidez deixam muito mais evidentes as alterações nas paisagens do que processos que estão ocorrendo de forma lenta, contínua e quase que imperceptível. Por exemplo, as erupções vulcânicas, terremotos, escorregamentos, dentre outros. No entanto, lentamente, tudo está em constante transformação. As montanhas se elevam por conta da convergência de placas tectônicas ou diminuem pela erosão. O vento, o sol, a chuva, o calor e o frio alteram as paisagens, mesmo que de forma imperceptível aos nossos olhos. Em diferentes proporções e escalas de tempo, os processos geológicos são a expressão de uma Terra dinâmica, viva! Por conta disso, são importantes elementos da geodiversidade de determinado local.

Na região de Piraí da Serra, além do Arco de Ponta Grossa e de processos erosivos que esculturaram o relevo, outros processos importantes na configuração da paisagem são o ciclo hidrológico e a pedogênese, destacando assim intemperismo e erosão dentro das demais etapas do ciclo exógeno. Por outro viés, estes processos também são importantes por proporcionarem a sustentação dos ecossistemas e por garantirem a relação homem-geodiversidade no que se refere ao uso do solo para agricultura, a pecuária, no abastecimento de água, etc. 


\section{Ciclo Hidrológico}

A ação que esculpe formas de relevo na superfície terrestre é considerada um tipo de atividade geológica orientada pela dinâmica externa do nosso planeta, conhecida como ação geomórfica (KARMANN, 2009). A água é apontada como o agente mais comum e importante na esculturação da paisagem. O movimento da água subterrânea somado ao movimento das águas em superfície pode ser considerado então um dos principais agentes geomórficos da Terra.

A dinâmica da água na natureza é entendida por meio do ciclo hidrológico, que compreende o transporte da água evaporada dos oceanos e dos continentes para a atmosfera, e desta novamente para os oceanos e continentes por meio dos vários tipos de precipitação (chuva, neve, granizo). A água que atinge a superfície da Terra pode infiltrar diante de condições favoráveis de topografia, cobertura vegetal e porosidade do solo. Nesta condição a água irá abastecer os lençóis subterrâneos, bem como alimentar os corpos de água superficiais. Em excesso pode encharcar os solos e causar problemas de grandes proporções, com alterações na paisagem (escorregamentos e outros). Ao atingir o nível freático, a água se desloca para as porções inferiores das vertentes em superfície, como fluxo de retorno, originando uma zona saturada e pantanosa ou áreas de nascentes dos rios (BIGARELLA, 2007).

A ocorrência de depressões úmidas e outras áreas saturadas em Piraí da Serra é parte do caminho que a água percorre na natureza, e está intimamente relacionada à formação dos ORGANOSSOLOS, a estocagem de carbono e as espécies vegetais de campos úmidos. A água subterrânea representa ainda um importante recurso natural, como o Aquífero Estrutural Furnas, que pode ser explorado por meio de diversas formas de abastecimento (domiciliar, irrigação, dentre outros).

A água que atinge a rocha nua ou terrenos impermeáveis tende a correr sobre a superfície em direção aos canais de drenagem. No percurso ela atua como um fator importante nos processos de intemperismo das rochas, na formação dos solos e no desencadeamento de processos erosivos. Especificamente no Arenito Furnas, a água meteórica percola pelas fissuras e se acumula em pequenas depressões da rocha, agindo na dissolução do cimento que une os grãos do arenito. Sua ação resulta em um grande leque de microfeições de relevo e, em outras proporções e escalas de tempo, influenciam também nos processos erosivos que continuam atuando no recuo do Escarpamento Furnas e nas macrofeições a ele associadas (canyons, morros-testemunhos).

\section{Pedogênese}

Segundo Melfi e Montes (2008, p. 113) “a pedogênese se faz sentir na parte superior do saprólito, possibilitando a transformação de um material friável, móvel, anidro, mineral e abiótico em um corpo organizado, friável, poroso, hidratado, mineral e orgânico". É um processo que atua em conjunto com o intemperismo das rochas, influenciado por fatores como o clima, rocha-matriz, organismos, topografia e tempo.

Os solos são a base para o desenvolvimento dos organismos vivos autotróficos e para a grande maioria das espécies vegetais, inclusive na sustentação das atividades humanas, que no caso específico de Piraí da Serra, fundamentam-se na agricultura e na pecuária. Os solos são importantes componentes dos ciclos do carbono e do nitrogênio. Suas funções ainda se expandem para o contato direto com a litosfera, influenciando no desenvolvimento do intemperismo, por meio do suprimento de água para o processo. Interfere na formação do relevo e pode ser um agente importante na formação de rochas e jazidas minerais (MELFI; MONTES, 2008)

É importante destacar que os solos com maior desenvolvimento pedogenético são os LATOSSOLOS e CAMBISSOLOS, distribuídos na faixa norte da área e os menos evoluídos sãos os NEOSSOLOS, presentes na maior parcela da região, sobre a Formação Furnas.

\section{Conclusões}

A região de Piraí da Serra é marcada por paisagens únicas que estão intimamente ligadas às litologias presentes na área, bem como ao forte controle estrutural associado ao Arco de Ponta Grossa. A geodiversidade da área é representada pelas rochas do Embasamento da Bacia do Paraná (Grupo Castro), da Bacia do Paraná (formações Iapó, Furnas e Ponta Grossa) e do Magmatismo Serra Geral 
(principalmente diques de diabásio). Os tipos de solos incluem representantes das classes dos NEOSSOLOS, CAMBISSOLOS, LATOSSOLOS, ARGISSOLOS e ORGANOSSOLOS. Dentre as principais formas de relevo, destacam-se os canyons, escarpamentos, morros-testemunhos, cachoeiras e um grande leque de feições de relevo ruiniforme. $\mathrm{O}$ registro fossilífero não chega a ser abundante, representado principalmente pelas ocorrências de icnofósseis na Formação Furnas. Além do Arco de Ponta Grossa, o ciclo hidrológico e a pedogênese são processos geológicos importantes na geração dos materiais englobados no conceito de geodiversidade para esta região.

A caracterização do meio abiótico resultou em uma descrição de seus elementos e a indicação de locais representativos na área de estudo. Estes procedimentos constituem-se nos alicerces de qualquer ação de geoconservação a ser pensada para Piraí da Serra, assim como pode ser desdobrada em trabalhos mais aprofundados acerca de algum aspecto particular do meio abiótico da região.

\section{Agradecimentos}

Agradecimentos à Fundação Araucária que financiou o projeto que deu origem a este trabalho. Os autores Nair Fernanda Mochiutti e Rafael Köene, bolsistas de iniciação científica no período de realização do projeto agradecem à Fundação Araucária e ao CNPq pelo apoio.

\section{Referências}

ASSINE, M. L. Aspectos da estratigrafia das sequências Pré-Carboníferas da Bacia do Paraná no Brasil. São Paulo, 1996. 207 p. Tese (Doutorado em Geologia Sedimentar) - Instituto de Geociências, Universidade de São Paulo.

Fácies, icnofósseis, paleocorrentes e sistemas deposicionais da Formação Furnas no flanco sudeste da Bacia do Paraná. Revista Brasileira de Geociências, São Paulo, v. 29, n. 3, p. 357-370, 1999.

; ALVARENGA, C. J. S.; PERINOTTO, J. A. Formação Iapó: Glaciação continental no limite Ordoviciano/Siluriano da Bacia do Paraná. Revista Brasileira de Geociências, São Paulo, v. 28, n. 1, p. 51-60, 1998.

BIGARELLA, J. J. Processos erosivos. In: BIGARELLA, J. J. Estrutura e origem das paisagens tropicais e subtropicais. 2 ed. Florianópolis: Editora da UFSC, v.3, 2007. p.883-940.

BRILHA, J. Património Geológico e Geoconservação: a conservação da natureza na sua vertente geológica. Lisboa: Palimage, 2005. $190 \mathrm{p}$.

DGTC - Departamento de Geografia, Terras e Colonização do Estado do Paraná. Levantamento aerofotogramétrico do Estado do Paraná: fotos aéreas. Curitiba: 1962/1963. 18 fotografias aéreas. Escala 1:70.000.

EMBRAPA - Empresa Brasileira de Pesquisa Agropecuária. Levantamento Semidetalhado de solos. Rio de Janeiro. 2002. Município de Castro - Estado do Paraná. Escala 1:100.000. Disponível em: < http://www.cnps.embrapa.br/ solosbr/publicacao.html>. Acesso em: 01 jul. 2008.

EMBRAPA - Empresa Brasileira de Pesquisa Agropecuária. Levantamento Semidetalhado de solos. Rio de Janeiro. 2002. Município de Piraí do Sul - Estado do Paraná. Escala 1:100.000. Disponível em: < http://www.cnps.embrapa.br/ solosbr/publicacao.html $>$. Acesso em: 01 jul. 2008.

EMBRAPA - Empresa Brasileira de Pesquisa Agropecuária. Levantamento Semidetalhado de solos. Rio de Janeiro. 2002. Município de Tibagi - Estado do Paraná. Escala 1:100.000. Disponível em: < http://www.cnps.embrapa.br/ solosbr/publicacao.html>. Acesso em: 01 jul. 2008.

FERNANDES, A. C. S. et al. Guia dos icnofósseis de invertebrados do Brasil. Rio de Janeiro: Interciência, 2002. $260 \mathrm{p}$.

GRAY, M. Geodiversity: valuing and conserving abiotic nature. Chichester: Wiley, 2004. 434 p.

GUIMARÃES, G. B. et al. Geologia dos Campos Gerais. In: MELO, M. S.; MORO, R. S.; GUIMARÃES, G. B. (Eds.) Patrimônio Natural dos Campos Gerais do Paraná. Ponta Grossa: Editora UEPG, 2007. p. 23-32.

HORNES, K. L. Caracterização geomorfológica da RPPN Itaytyba como subsídio para a implantação do turismo geológico. Ponta Grossa, 2003. 106 p. Trabalho de Conclusão de Curso (Graduação em Geografia) Universidade Estadual de Ponta Grossa.

HORNES, K. L. A paisagem e o potencial turístico no município de Tibagi: A Fazenda Santa Lídia do Cercadinho - um estudo de caso (PR). Maringá, 2006. 215 p. Dissertação (Mestrado em Análise Ambiental). Programa de Pós Graduação em Geografia, Universidade Estadual de Maringá.

KARMANN, I. Água: ciclo e ação geológica. In: TEIXEIRA, W. et al. Decifrando a Terra. 2 ed. São Paulo: Companhia Editora Nacional, 2009. p. 186-209.

KÖENE, R. et al. Caracterização do meio abiótico da Região de Piraí da Serra, Pr. In: CONGRESSO BRASILEIRO DE GEOLOGIA, 44, 2008, Curitiba. Anais... Curitiba: SBG, 2008. p.365-365. 
MAACK, R. Breves notícias sobre a geologia dos Estados do Paraná e Santa Catarina. Arquivos de Biologia e Tecnologia. Curitiba, v. 2, p. 63-154, 1947.

MARINI, O. J.; FUCK, R. A.; TREIN, E. Intrusivas básicas Jurássico-Cretáceas do Primeiro Planalto do Paraná. In: BIGARELlA, J. J.; SALAMUNI, R.; PINTO, V. M. Geologia do Pré-Devoniano e Intrusivas subseqüentes da porção oriental do Estado do Paraná. Curitiba: Boletim Paranaense de Geociências, n. 23-25, 1967, p.307-324.

MELFI, A. J.; MONTES, C. R. Solo e ambiente. In: MACHADO, R. (Org.). As ciências da Terra e sua importância para a humanidade: a contribuição brasileira para o Ano Internacional do Planeta Terra - AIPT. 1 ed. Curitiba: SBG, 2008. p. 107-126.

MELO, M. S. Formas rochosas do Parque Estadual de Vila Velha. Ponta Grossa: Editora UEPG, 2006. 145 p.

. et al. Piraí da Serra: proposta de nova unidade de conservação nos Campos Gerais do Paraná. Publicatio, Ponta Grossa, v.3, n.4, p. 85-94, set/dez. 2004.

. et al. Relevo e hidrografia dos Campos Gerais. In: MELO, M. S.; MORO, R. S.; GUIMARÃES, G. B. (Eds.) Patrimônio Natural dos Campos Gerais do Paraná. Ponta Grossa: Editora UEPG, 2007, 49-58.

. ; GuimarÃes, G. B.; SANTANA, A. C. Fisiografia da bacia do rio Pitangui. In: GEAHL, A. M.; MELO, M. S.; MORO, R. S. (Orgs.) Pitangui, rio de contrastes: seus lugares, seus peixes, sua gente. Ponta Grossa: Editora UEPG, 2010, 11-21.

MILANI, E. J. et al. Bacia do Paraná. Boletim de Geociências da Petrobras, Rio de Janeiro, v. 15, n. 2, p. 265-287, maio/nov. 2007.

MINEROPAR - Minerais do Paraná. Cartas Geológicas do Estado do Paraná. Curitiba. 2006. Folha Telêmaco Borba. Escala 1:250.000. Disponível em: <http://www.mineropar. pr.gov.br/arquivos/File/MapasPDF/Geologocos/telemaco_ borba.PDF. . . Acesso em: 01 jul 2008.

MINISTÉRIO DO EXÉRCITO - Departamento de Engenharia e Comunicações - Diretoria de Serviço Geográfico da Região Sul do Brasil. Porto Alegre. DSG. 1997. Folha Monte Negro. Escala 1:50.000.

MINISTÉRIO DO EXÉRCITO - Departamento de Engenharia e Comunicações - Diretoria de Serviço Geográfico da Região Sul do Brasil. Porto Alegre. DSG. 1997. Folha Rincão da Ponte. Escala 1:50.000.

NANUNCIO, V. M; MORO, R. S. O mosaico da vegetação remanescente em Piraí da Serra, Campos Gerais do Paraná: uma abordagem preliminar da fragmentação natural da paisagem. Terra Plural, Ponta Grossa, v. 2, n. 1, p. 155168, jan/jun 2008. Disponível em: <http://200.201.9.18/ index.php?journal $=$ tp $\&$ page $=$ article $\&$ op $=$ viewArticle $\&$ pat $\mathrm{h} \% 5 \mathrm{~B} \% 5 \mathrm{D}=397>$. Acesso 05 ago. 2009.
PEREIRA, F. C. Controle fisiográfico do patrimônio arqueológico da região de Piraí da Serra-PR. In: ENCONTRO ANUAL DE INICIAÇÃO CIENTÍFICA, 18, 2009, Londrina. Anais eletrônicos... Londrina: UEL, 2009a. Disponível em: <http://www.uel.br/eventos/eaic/ index.php?op=pesq $>$. Acesso em: 20 ago. 2009.

PEREIRA, F, C. As Pinturas rupestres da região de Piraí da Serra - Paraná. Ponta Grossa, 2009b. 120 p. Trabalho de Conclusão de Curso (Graduação em Geografia), Universidade Estadual de Ponta Grossa.

SÁ, M. F. M. Os solos dos Campos Gerais. In: MELO, M. S.; MORO, R. S.; GUIMARÃES, G. B. (Eds.) Patrimônio Natural dos Campos Gerais do Paraná. Ponta Grossa: Editora UEPG, 2007. p. 73-84.

SHARPLES, C. Concepts and principles of Geoconservation. Tasmanian Parks and Wildlife Service website, 2002. Disponível em: <http://www.dpiw.tas. gov.au/inter.nsf/Attachments/SJON-57W3 YM/\$FILE/ geoconservation.pdf $>$. Acesso em: 13 fev. 2009.

SOUZA, C. R. G.; SOUZA, A. P. Escarpamento Estrutural Furnas, SP/PR - raro sítio geomorfológico brasileiro. In: SCHOBBENHAUS, C. et al. (Eds.) Sítios geológicos e paleontológicos do Brasil. Brasília: DNPM, 2002. p. 299-306.

TREIN, E; FUCK, R. A. O Grupo Castro. In: BIGARELLA, J. J.; SALAMUNI, R.; PINTO, V. M. Geologia do PréDevoniano e Intrusivas subseqüentes da porção oriental do Estado do Paraná. Curitiba: Boletim Paranaense de Geociências, n. 23-25, 1967, p.257-303.

VIEIRA, A. J. Geologia do centro e nordeste do Paraná e centro-sul de São Paulo. In: CONGRESSO BRASILEIRO DE GEOLOGIA, 27, 1973, Aracaju. Anais... Aracaju: SBG, 1973. v.3, p.259-277. 